\title{
Trace oxygen shifts nitrogen metabolism and stimulates nitrogen reduction in low-oxygen marine waters.
}

\author{
JULIA HUGGINS ${ }^{1}$, CÉLINE MICHIELS ${ }^{2}$, RACHEL \\ SIMISTER $^{1}$ AND SEAN CROWE ${ }^{1}$
}

${ }^{1}$ University of British Columbia

${ }^{2}$ SRK consulting

Presenting Author: julia.a.huggins@gmail.com

The oceans are currently losing $\mathrm{O}_{2}$, which may have dramatic effects on global climate and biodiversity. As the $\mathrm{O}_{2}$ in marine environments is depleted to near anoxia, microorganisms transition from $\mathrm{O}_{2}$-based to several possible $\mathrm{NO}_{\mathrm{x}}^{-}$-based metabolisms: denitrification, anammox, and dissimilatory nitrite reduction to ammonium (DNRA). These three metabolisms have different geochemical outcomes, including nitrogen loss, carbon oxidation, and production of reduced compounds, which can, in turn, lead to changes in biological activity that may either exacerbate or mitigate $\mathrm{O}_{2}$ loss. The net consequences of marine $\mathrm{O}_{2}$-loss may therefore depend on which $\mathrm{NO}_{\mathrm{x}}{ }^{-}$-based metabolisms engage as $\mathrm{O}_{2}$ is depleted. The regulation of $\mathrm{NO}_{\mathrm{x}}^{-}$-based metabolisms under low $\mathrm{O}_{2}$ has received little attention, however, because it is generally assumed that $\mathrm{NO}_{\mathrm{x}}^{-}$-reduction only occurs in the absence of $\mathrm{O}_{2}$. The threshold for anoxia is typically defined by an analytical detection limit of $1-2 \mu \mathrm{M} \mathrm{O}_{2}$, despite evidence that $\mathrm{NO}_{\mathrm{x}}{ }^{-}$reduction occurs both above and below this limit. Here, we use stable nitrogen isotope $\left({ }^{15} \mathrm{~N}\right)$ incubations of seawater collected from a model anoxic marine environment (Saanich Inlet, $\mathrm{BC}$ ) to determine the rates and pathways of $\mathrm{NO}_{\mathrm{x}}^{-}$reduction under both anoxic conditions and within a highresolution range of low $\mathrm{O}_{2}$ conditions $(0.1-10 \mu \mathrm{M})$. We show that multiple pathways of $\mathrm{NO}_{\mathrm{x}}^{-}$-reduction can co-occur in the presence of low $\mathrm{O}_{2}$, and that these pathways have different activity thresholds between $4-8 \mu \mathrm{M} \quad \mathrm{O}_{2}$. Furthermore, we demonstrate that rates of denitrification and DNRA are highest under very low $\mathrm{O}_{2}$ concentrations $(0.1-2 \mu \mathrm{M})$ rather than fully anoxic conditions, which is a previously unrecognized interaction between $\mathrm{O}_{2}$ and $\mathrm{NO}_{\mathrm{x}}{ }^{-}$-reduction. We also observed a trade-off between the rates of denitrification and DNRA across these very low $\mathrm{O}_{2}$ concentrations, revealing interactions between competing pathways that would normally be overlooked in studies with low-resolution in $\mathrm{O}_{2}$. The activity of $\mathrm{NO}_{\mathrm{x}}^{-}$-reduction under environmental conditions that could support co-occuring $\mathrm{N}$-oxidation raises the possibility of cryptic $\mathrm{N}$-cycling and highlights the need for more complex process-rate measurements in ${ }^{15} \mathrm{~N}$ incubations. These findings have implications for the biogeochemical models that predict microbial metabolic responses to ocean deoxygenation and their ecological impacts. 